Article

\title{
Performance Evaluation of Wire Cloth Micro Heat Exchangers
}

\author{
Hannes Fugmann ${ }^{1, *(\mathbb{D})}$, Sebastian Martens ${ }^{2}$, Richard Balzer ${ }^{3}$, Martin Brenner ${ }^{4}$, Lena Schnabel ${ }^{1}$ \\ and Carsten Mehring 2,* (D) \\ 1 Fraunhofer ISE-Institute for Solar Energy Systems, Heidenhofstr. 2, 79110 Freiburg, Germany; \\ hannes.fugmann@ise.fraunhofer.de (H.F.); lena.schnabel@ise.fraunhofer.de (L.S.) \\ 2 IMVT-Institute of Mechanical Process Engineering, University of Stuttgart, Böblinger Str. 72, \\ 70199 Stuttgart, Germany; sebastian.martens@imvt.uni-stuttgart.de (S.M.); \\ Carsten.Mehring@imvt.uni-stuttgart.de (C.M.) \\ 3 Spörl KG Präzisionsdrahtweberei, Staudenweg 13, 72517 Sigmaringendorf, Germany; \\ richard.balzer@spoerl.de \\ 4 MAHLE International GmbH, Heilbronner Str. 393-397, 70469 Stuttgart, Germany; \\ martin.brenner@mahle.com \\ * Correspondence: hannes.fugmann@ise.fraunhofer.de (H.F.); Carsten.Mehring@imvt.uni-stuttgart.de (C.M.); \\ Tel.: +49-761-4588-2353 (H.F.)
}

Received: 1 December 2019; Accepted: 28 January 2020; Published: 6 February 2020

\begin{abstract}
The purpose of this study is to validate a thermal-hydraulic simulation model for a new type of heat exchanger for mass, volume, and coolant/refrigerant charge reduction. The new heat exchanger consists of tubes with diameters in the range of $1 \mathrm{~mm}$ and wires in the range of $100 \mu \mathrm{m}$, woven together to form a $200 \times 200 \times 80 \mathrm{~mm}^{3}$ wire cloth heat exchanger. Performance of the heat exchanger has been experimentally evaluated using water as inner and air as outer heat transfer medium. A computational thermal and fluid dynamic model has been implemented in OpenFOAM ${ }^{\circledR}$. The model allows variation of geometry and operating conditions. The validation of the model is based on one single geometry with an opaque fabric and air-side velocities between 1 and $7 \mathrm{~m} / \mathrm{s}$. The simulated and measured pressure drops are found to be in good agreement with a relative difference of less than $16 \%$. For the investigated cases, the effective heat transfer coefficients are in very good agreement (less than 5\%) when adapting the contact resistance between tubes and wires. The numerical model describes the fluid flow and heat transfer of the tested heat exchanger with adequate precision and can be used for future wire cloth heat exchanger dimensioning for a variety of applications.
\end{abstract}

Keywords: heat exchanger; performance evaluation; micro tubes; wire structure; computational fluid dynamics; heat transfer enhancement; dimensioning

\section{Introduction}

In recent decades, heat exchanger design and development focused on various aspects in order to improve heat transfer processes. In general, the improvements are related to (i) pumping or fan power reduction, (ii) volume reduction, and (iii) mass reduction, with an increase in (iv) heat transfer surface area and $(\mathrm{v})$ in heat transfer coefficients.

Extended surface plate-fin and tube-fin heat exchangers experienced enhanced miniaturization to achieve the mentioned improvements. A reduction in pressure drop can be achieved by increasing the frontal face area and decreasing the flow length. Volume reduction is presently essential for charge reduction of new and natural refrigerants. Mass reduction is realized by decreasing tube and fin thicknesses down to $100 \mu \mathrm{m}$ and less. A heat transfer coefficient and surface area increase is achieved 
by decreasing the fin pitches to dimensions around or below $1 \mathrm{~mm}$ and by geometrical modification of the fins (e.g., louvered, wavy, or offset strip fins).

In order to significantly increase heat transfer coefficients, wire structures are being investigated as heat transfer enhancements. Metallic woven-wire mesh structures [1-5], pin fin structures [6,7] and screen-fin structures [8] were designed for flat primary surfaces. One air-to-air heat exchanger is manufactured and marketed by Vision4Energy [9], numerical performance evaluations of metallic woven-wire mesh structures were presented in [10,11]. Kumra et al. and Lee et al. [12,13] analyzed wire-on-tube type heat exchangers with wires being welded on top of both sides of a heat transfer tube.

Previous studies concentrated either on woven-wire meshes or single wires with diameter in the order of $1 \mathrm{~mm}$. The first design lacks in good thermal conductivity within the wire mesh due to insufficient thermal contact between the wires; the second design does not show high heat transfer coefficients on the wires due to the relatively large wire diameter. Attempts to decrease the wire diameter significantly for the second design are effortful [6,7]. New designs are needed, which make use of the fast and well developed weaving process, without having wires in the mesh which do not contribute to the heat transfer process.

Such possible design concepts are detailed in [14,15]. The wire diameters in these (patented) heat exchangers primarily range from $100 \mu \mathrm{m}$ to $1 \mathrm{~mm}$. The heat exchanger design, analyzed in this paper, follows these designs and uses a wire diameter of $200 \mu \mathrm{m}$. In the manufacturing process of the wire cloth the micro tubes (hollow wires) and the wire structure (solid wires) are woven together on an adopted loom, similar to the weaving process known from textile manufacturing [16]: the tubes are processed as weft threads, the wires as warp threads in a standard linen weave. The large-scale wire cloth is thereafter cut to size. The micro tubes can be manufactured with diameters well below $2 \mathrm{~mm}$ [17] and wall thicknesses below $100 \mu \mathrm{m}$. The resulting geometry provides small volume specific masses and high volume specific surface areas on both fluid sides. In addition, the pressure stability of the micro tubes is ensured at high pressures. A variety of applications are addressed with the wire cloth micro heat exchanger. These include applications such as heating and cooling of automotive as well as air conditioning of buildings. The heat exchanger might be beneficial when volume in air flow direction is strongly limited (e.g., in engine compartments or building walls).

In this paper, we present thermal and flow measurements of a sample heat exchanger and computational results from a fluid dynamic simulation of the air-side flow through the heat exchanger coupled with a heat transfer simulation.

\section{Methods}

Performance of the heat exchanger has been determined by simulation and by experimental analysis. Therefore several samples of wire fabrics have been manufactured. A schematic of a section of the wire cloth heat exchanger is shown in Figure 1.

\subsection{Test Hardware}

In this study only one of the fabrics is analyzed. The sample, as implemented into the heat exchanger, is shown in Figure 2. The heat exchanger properties are listed in Table 1. The main difficulty in manufacturing the wire cloth was wire breakage due to the large size differences of tubes and wires and the resulting mechanical stress in the wire; especially for aluminium wires. The second challenge was to roll up the wire cloth continuously after the weaving process without displacement of the wires on the tubes. Again due to the size differences between tubes and wires, the rolling process for the wire cloth differed from standard fabrics. The third difficulty was to provide sufficient mechanical contact between the tubes and the wires through the contacting process. The contacting was realized by diffusion bonding for the stainless steel variant. Lastly, the insertion of the tubes into the header/collector plates was very time consuming. In particular, burs on the tube endings and non-uniform tube distances had to be dealt with. 


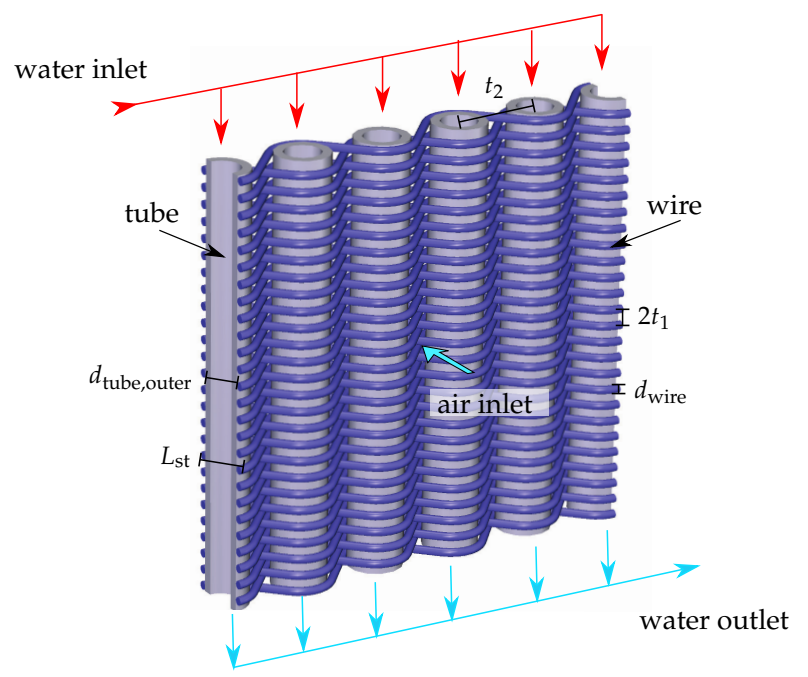

Figure 1. Schematic of a section of the wire cloth used in the air-to-water heat exchanger. Dimensions for the tested sample are given in Table 1.
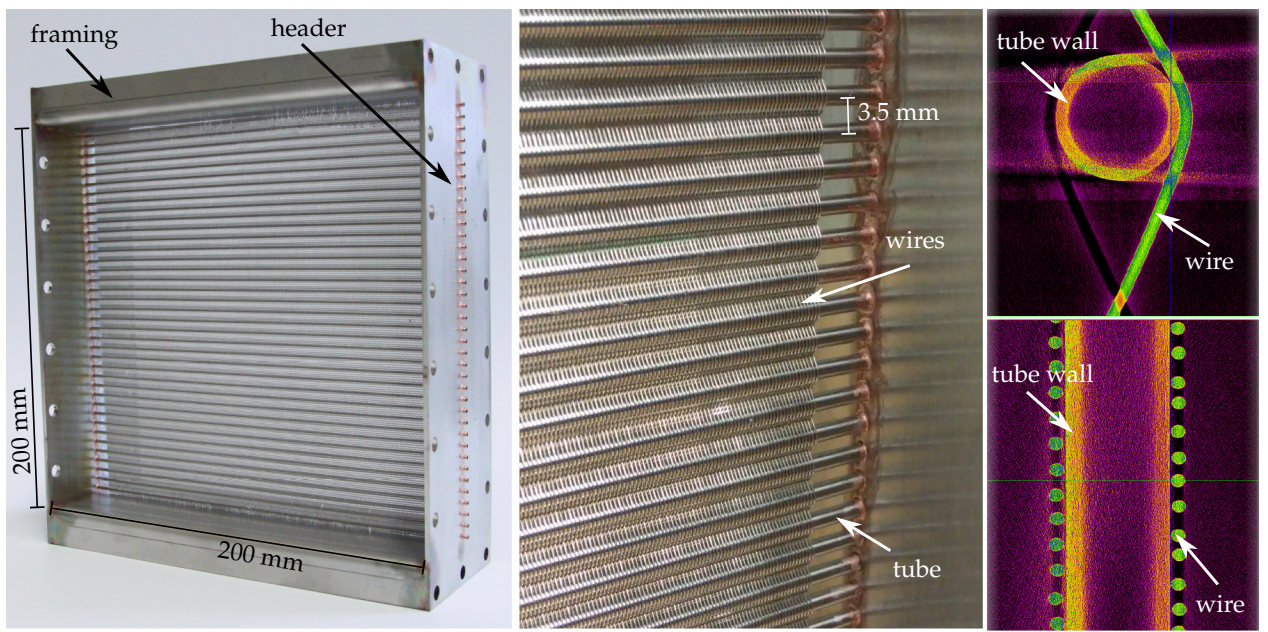

Figure 2. Wire cloth heat exchanger. Left: Heat exchanger with frame. Middle: Detail of the wire cloth and integration into the header/distributor plate. Right: Micro Computer Tomography views of the contact between wires and tube.

Table 1. Validation of the uncoupled simulations.

\begin{tabular}{llll}
\hline Specification & Parameter & Unit & Wire Structure \\
\hline material & - & - & stainless steel \\
thermal conductivity & $k_{\text {solid }}$ & $\mathrm{W} /(\mathrm{m} \mathrm{K})$ & 20 \\
number of tubes & $n_{\text {tubes }}$ & - & 57 \\
width of heat exchanger & $W_{\text {HXelm }}$ & $\mathrm{mm}$ & 200 \\
height of heat exchanger & $H_{\mathrm{HXelm}}$ & $\mathrm{mm}$ & 200 \\
length of structure in flow direction & $L_{\text {st }}$ & $\mathrm{mm}$ & 2.4 \\
outer diameter tubes & $d_{\text {tube,outer }}$ & $\mathrm{mm}$ & 2 \\
tube wall thickness & $d_{\text {wall }}$ & $\mathrm{mm}$ & 0.2 \\
tube pitch perpendicular to flow direction & $t_{2}$ & $\mathrm{~mm}$ & 3.5 \\
wire diameter & $d_{\text {wire }}$ & $\mu \mathrm{m}$ & 200 \\
wire pitch perpendicular to flow direction & $t_{1}$ & $\mu \mathrm{m}$ & 200 \\
heat transfer surface area & $A_{\mathrm{HTS}}$ & $\mathrm{m}^{2}$ & 0.2227 \\
heat transfer surface area density & $\beta$ & $\mathrm{m}^{2} / \mathrm{m}^{3}$ & 2320 \\
\hline
\end{tabular}


The standard deviation of the wire pitch $t_{1}$ of the final wire fabric is $5 \mu \mathrm{m}$; analyzed via microscope images of five different areas on the wire fabric, each area representing one tube and more than 30 wires. Maximum deviations from the target value of $t_{1}=200 \mu \mathrm{m}$ is $10 \mu \mathrm{m}$. For the tube pitch $t_{2}=3.5 \mathrm{~mm}$ the standard deviation is $0.07 \mathrm{~mm}$. Thus, a strong influence on the fluid flow due to geometrical irregularities is not expected.

\subsection{Analysis Model}

Within the analysis model, three different regions are distinguished; (i) the fluid flow within the tubes, (ii) the structure itself, including tubes and wires, and (iii) the gas flow outside of the structure. Flow simulations are carried out, using a finite-volume, multi domain solver for conjugated heat transfer processes available in OpenFOAM ${ }^{\circledR}$. For efficiency and simplification purpose, the fluid flow in the pipes region is modeled using correlations for pressure loss (Euler number) and heat transfer (Nusselt number) available from literature [18].

\subsubsection{Governing Equations and Assumptions}

Heat transfer within the solid phase of the structure is described by a simple heat diffusion equation, i.e.,

$$
\frac{\partial T}{\partial t}=\frac{k}{c_{p}} \nabla^{2} T
$$

The solution to this equation and the relevant boundary conditions at the material surfaces is the time-dependent temperature distribution in the fabric, which depends on the thermal conductivity $k$ and heat capacity $c_{p}$ of the solid. The governing equations for the gas phase are the three-dimensional Navier-Stokes equations, which weresimplified by assuming laminar, incompressible flow of a Newtonian fluid with constant fluid properties and neglecting volumetric forces and radiation heat transfer. Accordingly, the equations for conservation of mass, momentum and energy are given by

$$
\begin{aligned}
\vec{\nabla} \cdot \vec{u} & =0 \\
\frac{\partial \vec{u}}{\partial t}+\vec{\nabla} \cdot(\vec{u} \vec{u}) & =-\frac{\vec{\nabla} p}{\rho}+\frac{1}{\rho} \vec{\nabla} \cdot \tau
\end{aligned}
$$

and

$$
\frac{\partial h}{\partial t}+\vec{\nabla} \cdot(\vec{u} h)=-\frac{\vec{\nabla} \dot{q}}{\rho}+\frac{1}{\rho} \vec{\nabla} \cdot(\tau \vec{u}),
$$

where $\vec{u}, \tau, p, \rho$ and $h$ denote the velocity vector, shear stress tensor, static pressure, gas density and gas enthalpy, respectively. Due to the rather low flow velocity, which result in specific Reynolds numbers lower than 1000, the fluid flow is suspected to be purely laminar inside of the fabric zone. Random fluctuations in the upstream flow would be reduced by the rapid acceleration of the flow when entering the fabric and also by the high shear stress in the fabric. For the case of a turbulent flow entering the wire-cloth heat exchanger, air-side heat transfer coefficients can be expected to be larger.

\subsubsection{Simulation Domain and Boundary Conditions}

To make the numerical analysis manageable, only a small geometrically periodic section of the wire cloth was analyzed, as shown in Figure 3. Effects due to flow and geometric non-uniformity near the distribution plates and the heat exchanger frame are not captured by the analysis. The analyzed domain consists of 2 half-wires and three (half-)tubes with the direction of the gas flow being perpendicular to the plane in which the tube axes lie, i.e. in positive $x$-direction according to Figure 3 . As shown in Figure 3 , the gas flow enters the domain at $X_{0}$ with fixed velocity and temperature, at $X_{1}$ the outlet pressure is fixed, while temperature and velocity gradients are set to zero. In $y$-direction, cyclic 
boundary conditions $(B C)$ are applied at $Y_{0}$ and $Y_{1}$, while in $z$-direction $\left(Z_{0}, Z_{1}\right)$ wall slip/symmetry $\mathrm{BCs}$ are applied for velocity and zero gradient for temperature. In the solid domain the temperature at the inner walls of the tubes $(I)$ is fixed. In other words, the heat transfer phenomenon on the liquid side within the tube has been excluded from the numerical analysis. At the interface $(W)$ between solid and gas phase, a special coupling BC is applied by solving Equation (5), ensuring energy conservation across the interface.

$$
\left.k_{\text {solid }} \frac{\partial T_{\text {solid }}}{\partial \vec{n}_{\text {int }}}\right|_{W}=-\left.k_{\text {air }} \frac{\partial T_{\text {air }}}{\partial \vec{n}_{\text {int }}}\right|_{W}
$$

Lastly, a solid-solid interface $(K)$ is introduced between the tubes and wires in order to account for the contact resistance between them. At the position of the red contact, shown in Figure 3, a heat flow dependent temperature difference results, as a consequence of assuming a wall of defined thermal conductivity and defined width and depth. the prescribed contact resistance is a result of the manufacturing process, where the wire cloth structure is mechanically and thermally enhanced by diffusion welding or soldering the tubes and the wires together. Ideally the effect of such measures is a very low thermal resistance; but due to deficiencies in the new manufacturing process of the thermal fabric, the resistance is quite substantial and therefore has to be taken into account in the simulation model.

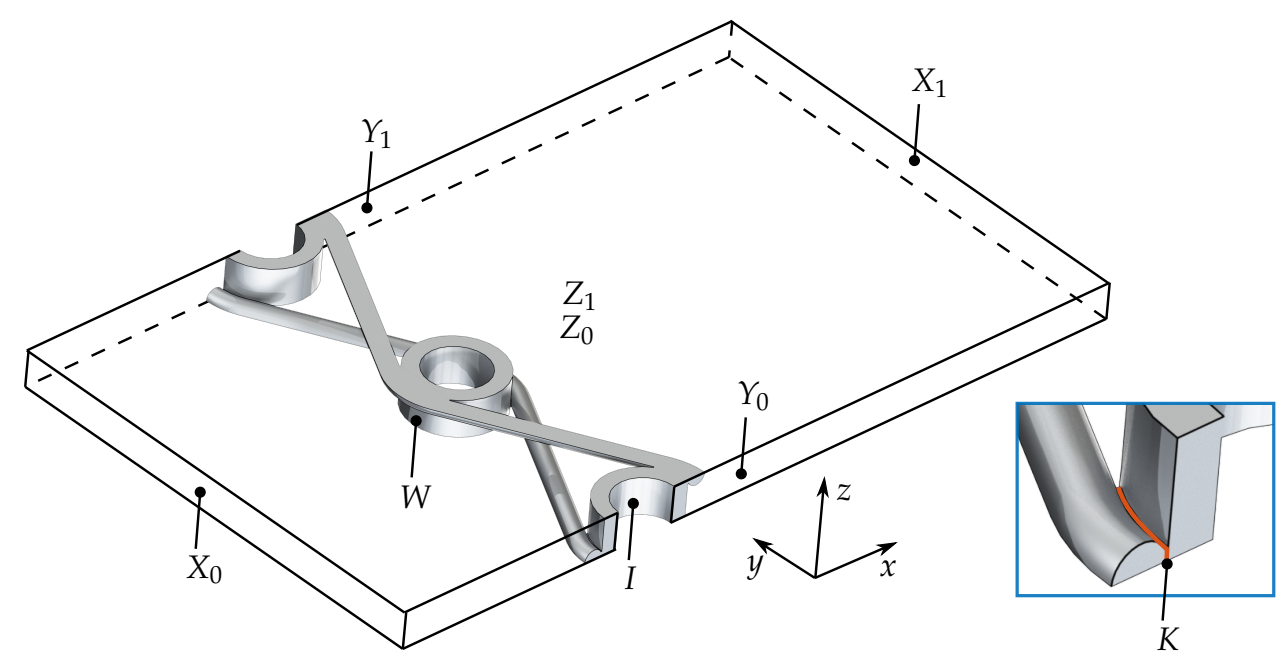

Figure 3. Schematic of the simulation area. Fabric inside fluid domain with boundaries $(X, Y, Z)$. Contact resistance $(\mathrm{K})$, interface between solid and fluid region $(\mathrm{W})$ and inner wall of the tubes (I) define the boundaries of the fabric.

For the simulations the Grid Convergence Method based on the Richardson extrapolation was used to determine the numerical uncertainty. Two key variables were defined: (i) the air-side pressure drop and (ii) the air-side outlet temperature. For all simulations, including additional geometries, the grid was refined such that the numerical uncertainty (fine-grid convergence index) for the key variables was less than $5 \%$.Thus, uncertainties related to the choice of grid are expected to be small. More information on the meshing, refinement and uncertainties can be found in Martens ([19], p. 37-43).

\subsubsection{One-Way Coupling between Momentum- and Energy-Equation}

The solution of the differential equations in the two domains is performed in two consecutive steps. In a first step, only the unsteady mass- and momentum conservation equations for the gas phase (Equations (2) and (3)) are solved assuming laminar incompressible flow. From this solution, the average pressure loss $\overline{\Delta p}$ across the wire cloth is calculated, and the temporal mean value of the velocity field $\bar{u}$ is stored. While velocity fluctuations affect the average pressure loss, their effect on heat transfer is found to be small. This is partly due to the large difference in heat capacities between 
the solid and the gas phase, which causes the temperature in the solid to remain almost constant over time, even at pronounced transient operating conditions, for example with vortex shedding in the gas phase behind the tubes and wires. The predicted separation behavior of the mean flow was found to result in an adequate prediction of the mean heat transfer. In a second step, the energy equations for the fluid (Equation (4)) and solid (Equation (1)) domains are solved on the basis of the time-averaged velocity field calculated in the first step. By decoupling the momentum and energy equations, it is possible to change properties of the solid phase and solve the heat transfer problem to good accuracy without having to recalculate the velocity field solution again.

Figure 4 shows an example of the predicted gas phase velocity field. In the left picture the distribution of the velocity $u(t)$ at a specific time $t$ during the simulation. Upstream and within the wire cloth structure, the velocity distribution appears symmetrical. Downstream, irregular flow structures are found due to vortex shedding. The calculated time-averaged velocity $\bar{u}$ is displayed in the middle picture of Figure 4 . The velocity distribution upstream and inside the wire cloth is virtually identical to the instantaneous velocity distribution. Downstream, behind the tubes, large symmetric flow separation zones are found. The standard deviation of the velocity $\hat{\sigma}(u)$ (right image in Figure 4) shows that significant transient structures are only present in the wake and thus have little effect on the gas-to-solid heat transfer.
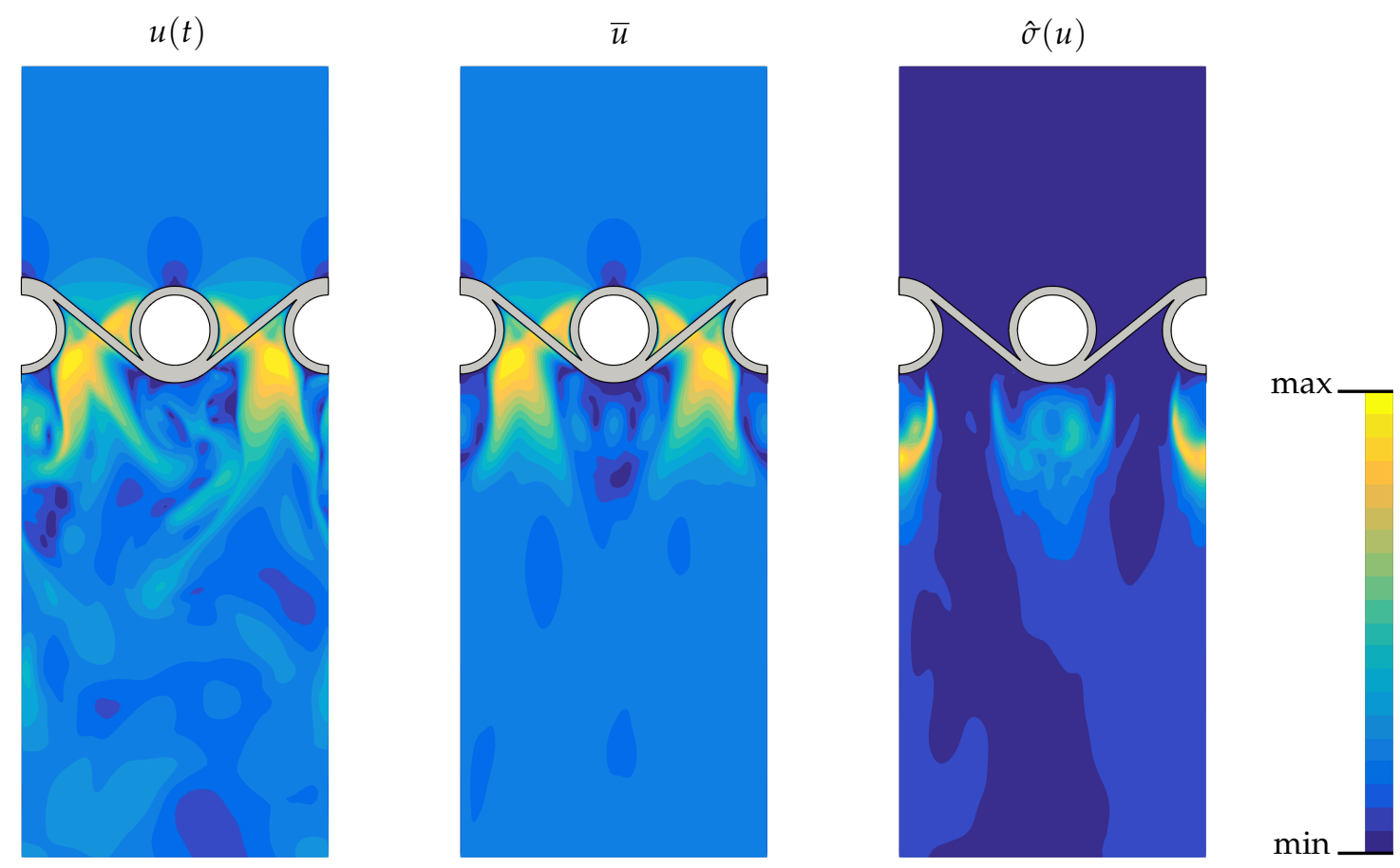

Figure 4. Gas phase velocity field from numerical simulation. Left: Velocity magnitude $u$ at time $t$, middle: temporal mean velocity $\bar{u}$ and right: temporal standard deviation of velocity magnitude $\hat{\sigma}(u)$.

In order to validate (a) the symmetry and periodicity assumptions imposed onto the selected computational domain and (b) the uncoupling of momentum and energy equations, several simulation runs on a larger domain were carried out with and without coupled solutions of Equations (1)-(5). The larger domain consisted of 5 times 10 symmetry units in $y$ - and $z$-direction, respectively, in order to enable vortex shedding in a larger unconstrained scale. By using large diameters for tubes and wires in addition to wide spacing and a high velocity we achieve large Reynolds numbers, which results in strongly transient flow behaviour. By using large diameter tubes and wires in addition to wider tube and wire spacings, high air-side inflow velocities occur and result in larger Reynolds numbers and potentially locally-turbulent flow through the cloth. Therefore the investigate scenario together 
with the employed assumptions represents a worst-case scenario with regards to the heat transfer capabilities of the system.

Table 2 summarizes the results of the described validation runs. With regards to the reference case, with large domain and coupled solution, the uncoupled solution differs by $5.3 \%$ in the air-side heat transfer coefficient $\bar{h}_{\text {air }}$, while the pressure loss is the same for both cases, because fluid temperature change due to the coupling is small for the investigated case. On the smaller domain, the pressure loss is found to be $3.6 \%$ higher than on the larger domain, while the heat transfer coefficient is lower in the coupled and uncoupled solution ( $2.2 \%$ and $2.1 \%$, respectively). Overall, the differences in the solutions are small, thus justifying the reduction of the computational domain (to one symmetry unit), the imposed BCs and the decoupling of the momentum and energy equations for the purpose of estimating the thermal performance of the wire-cloth.

Table 2. Validation of the uncoupled simulations.

\begin{tabular}{lcccc}
\hline$\#$ & Domain & Coupled? & $\delta \overline{\Delta p}$ & $\delta \overline{\boldsymbol{h}}_{\text {air }}$ \\
\hline ref. & large & yes & - & - \\
1 & large & no & & $5.3 \%$ \\
2 & small & yes & $3.6 \%$ & $-2.2 \%$ \\
3 & small & no & $3.6 \%$ & $-2.1 \%$ \\
\hline
\end{tabular}

\subsection{Experimental Set-Up}

The thermal-hydraulic performance of the wire-cloth was evaluated at a test rig at the Fraunhofer ISE. Air and water are used as working fluids. The test rig is described in detail in [3]. The specific measurement procedure for the wire cloth micro heat exchanger shall be explained briefly based on the schematic in Figure 5. A flow conditioning section delivers air at $25^{\circ} \mathrm{C}$ at volume flow rates of $150-1000 \mathrm{~m}^{3} / \mathrm{h}$. The air passes a straight DN280 tube and a DN280 bend, followed by a straight rectangular channel of $200 \mathrm{~mm} \times 200 \mathrm{~mm}$ with flow straighteners.

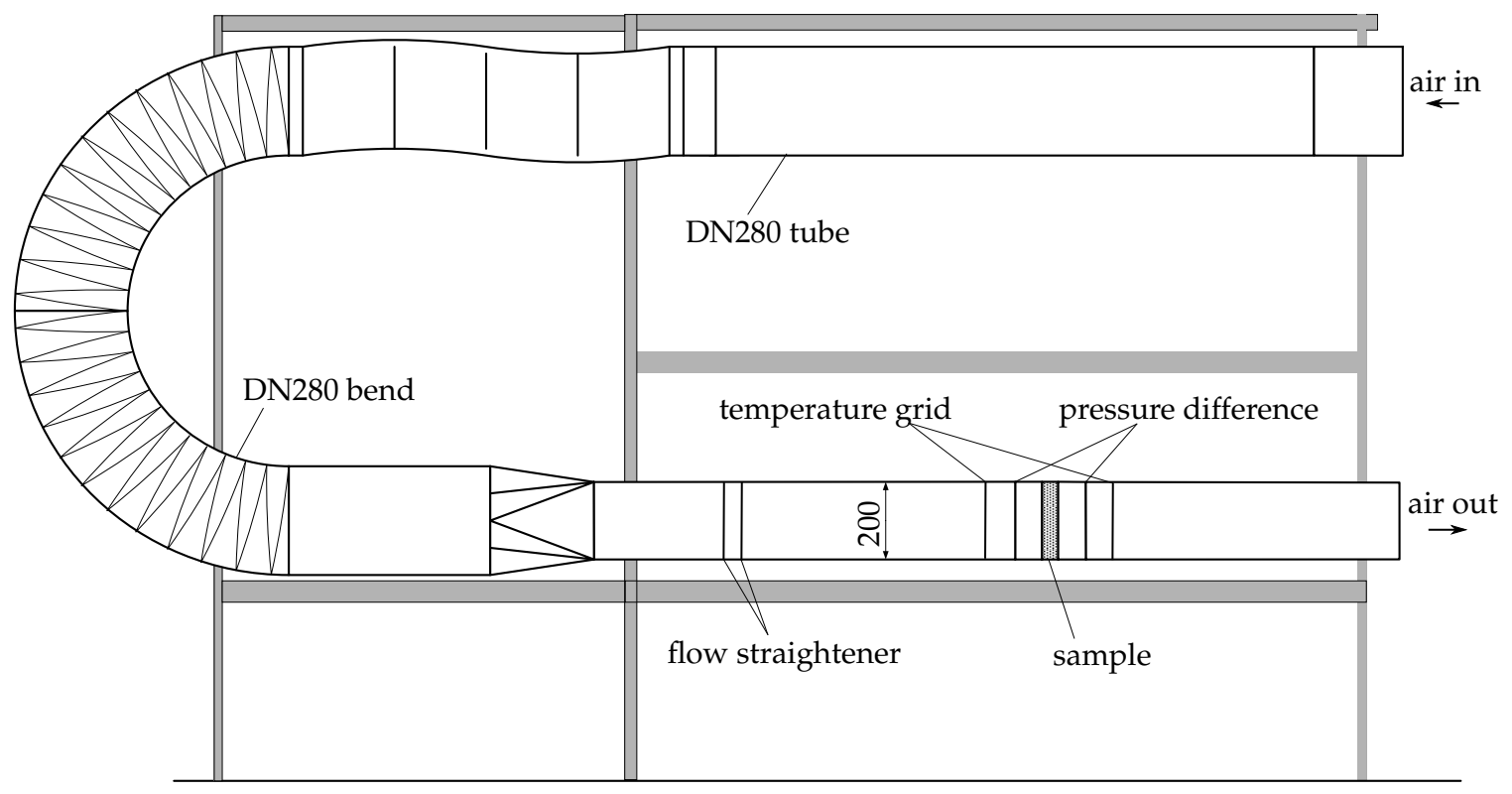

Figure 5. Schematic of the test rig.

In the test section, fast-response thin-film Pt100 temperature sensors are used. Four sensors are installed at the inlet and 12 at the outlet channel, respectively. The pressure drop across the sample is measured with two differential pressure transmitters with a measuring range of $0-250 \mathrm{~Pa}$ 
and $0-1000 \mathrm{~Pa}$, respectively. The entire testing section was leakage tested and thermally insulated. On the water-side, fluid temperature and volume flow rate is controlled by a heater unit and set to $85^{\circ} \mathrm{C}$ and $1.7 \mathrm{~m}^{3} / \mathrm{h}$. Here, Pt100 resistance temperature sensors and an electromagnetic flow sensor are employed. Pressure drop is measured via a differential pressure transmitter. For each measurement point, water and air side temperatures and velocities are kept constant for approximately $40 \mathrm{~min}$ prior to data collection, in order to assure steady conditions. After this time interval all quantities are averaged over a shorter time period to obtain a single performance value for each measurement point. More details on the major sensor technology is given in the Appendix B.

\subsection{Performance Parameters}

The heat transfer rate $\dot{Q}_{\mathrm{HX}}$ of the air to water heat exchanger required to calculate air-side performance characteristics can be expressed using three different equations, i.e.,

$$
\begin{gathered}
\dot{Q}_{\mathrm{HX}}=\dot{m}_{\mathrm{air}} c_{p, \text { air }} \Delta T_{\mathrm{air}}, \\
\dot{\mathrm{Q}}_{\mathrm{HX}}=\dot{m}_{\text {water }} c_{p, \text { water }} \Delta T_{\mathrm{water}}, \\
\dot{Q}_{\mathrm{HX}}=U_{\mathrm{HX}} A_{\mathrm{HTS}, \text { air }} \Delta T_{\mathrm{m}} .
\end{gathered}
$$

Here, the mass flow rates on the air-side $\dot{m}_{\text {air }}$ and water-side $\dot{m}_{\text {water }}$ and the temperature changes within the fluids across the heat exchanger $\Delta T_{\text {air }}$ and $\Delta T_{\text {water }}$ are determined experimentally. Thus Equation (6) or (7) can be used to calculate the heat transfer rate $\dot{Q}_{\mathrm{HX}}$ from the measured data. For the purpose of calculating heat transfer from simulation data, Equation (6) is used. The overall heat transfer coefficient $U_{\mathrm{HX}}$ in Equation (8) relates to the total heat transfer surface area $A_{\mathrm{HTS} \text {,air }}$ on the air side and the true (or effective) mean temperature difference $\Delta T_{\mathrm{m}}$ [20], i.e.,

$$
\Delta T_{\mathrm{m}}=\Delta T_{\log } F .
$$

The correction factor $F$ in the above equation can be determined based on the flow configuration and the operating conditions and the well-known logarithmic mean temperature difference (LMTD) $\Delta T_{\log }$ which is given by

$$
\Delta T_{\log }=\frac{\left(T_{\text {air,in }}-T_{\text {water,out }}\right)-\left(T_{\text {air,out }}-T_{\text {water,in }}\right)}{\log \frac{T_{\text {air,i, }}-T_{\text {water,out }}}{T_{\text {air,out }}-T_{\text {water, in }}}} .
$$

Therefore a combination of either Equation (6) or (7) with Equation (8) yields $U_{\mathrm{HX}}$. The air-side effective heat transfer coefficient $U_{\text {air,eff }}$ can be obtained from

$$
\frac{1}{U_{\text {air,eff }} A_{\mathrm{HTS}, \text { air }}}=\frac{1}{U_{\mathrm{HX}} A_{\mathrm{HTS}, \text { air }}}-\frac{1}{h_{\text {water }} A_{\mathrm{HTS}, \text { water }}}-\frac{d_{\text {wall }}}{k_{\text {solid }} A_{\text {wall }}} .
$$

The second term on the right-hand-side of Equation (11) indicates the water-side thermal resistance, with $h_{\text {water }}$ known from previous experimental work for the experimental data (cf. Appendix B); The second term is set to zero for simulation data with $T_{\text {water }}=T_{\text {water,in }}=T_{\text {water,out }}$ used in Equation (10). The third term on the right-hand-side of Equation (11) indicates the tube wall thermal resistance for thin walled tubes. All terms on the right hand side of Equation (11) can be determined from experimental or simulation data. The effective heat transfer coefficient $U_{\text {air,eff }}$ includes the conductive heat transfer through the wire and the convective heat transfer from the tube and the wire to the air. In general, $U_{\text {air,eff }}$ can be expressed by the product of extended surface efficiency $\eta_{0}$ and convection heat transfer coefficient $h_{\text {air. }}$. The efficiency $\eta_{0}$ is given by 


$$
\eta_{0}=\frac{A_{\text {wall,air }}}{A_{\mathrm{HTS}, \mathrm{air}}}+\eta_{f} \frac{A_{\mathrm{wire}, \mathrm{air}}}{A_{\mathrm{HTS}, \mathrm{air}}}
$$

where $\eta_{f}$ represents the fin efficiency of the wire structure and

$$
A_{\mathrm{HTS}, \text { air }}=A_{\text {wall,air }}+A_{\text {wire,air }} \text {. }
$$

A separation into the two factors $\eta_{0}$ and $h_{\text {air }}$ requires a valid calculation method for the efficienc $\eta_{f}$. Such a method is only available for well defined fin types [20]. For a wire cloth, several simplifying assumptions would be necessary to make use of the given methods. Thus, the experimental thermal performance data will be compared to simulation data by using the dimensional effective heat transfer coefficient $U_{\text {air,eff. }}$. To match the tested hardware a diffusion bonding zone between wires and tubes has been introduced in the simulation model. As an estimation of the bonding quality was not readily available, a parameter study on the thermal resistances $R$ of the bonding zone has been performed. The thermal behavior of the diffusion-bonding zone has been modelled like a wall as shown in Figure 6 . The relevant properties of the wall are the geometry (height $h_{\mathrm{b}}$, length $l_{\mathrm{b}}$ and thickness $w_{\mathrm{b}}$ ) and its thermal conductivity $k_{\mathrm{b}}$. Equation (14) defines the effective conductivity of the bonding zone:

$$
\frac{1}{R}=k_{\mathrm{b}} \frac{w_{\mathrm{b}}}{h_{\mathrm{b}}} l_{\mathrm{b}}
$$

The length of the wall $l_{\mathrm{b}}$ (cf. Figure A1) is derived from the geometry of the fabric and is equal to the bent part of the wire:

$$
l_{\mathrm{b}}=\left(d_{\text {wire }}+d_{\text {tube,outer }}\right) \arcsin \left(\frac{d_{\text {wire }}+d_{\text {tube,outer }}}{t_{2}}\right) .
$$

The height of the diffusion-bonding zone $h_{\mathrm{b}}$ has been discussed in [21-23]. Following the literature a value of $10 \mu \mathrm{m}$ has been used here. Height and width are coupled via geometric relations:

$$
\begin{aligned}
\varphi\left(h_{\mathrm{b}}\right) & =\arccos \left(1-2 h_{\mathrm{b}} / d_{\text {wire }}\right), \\
w_{\mathrm{b}}(\varphi) & =d_{\text {wire }} \sin \varphi .
\end{aligned}
$$

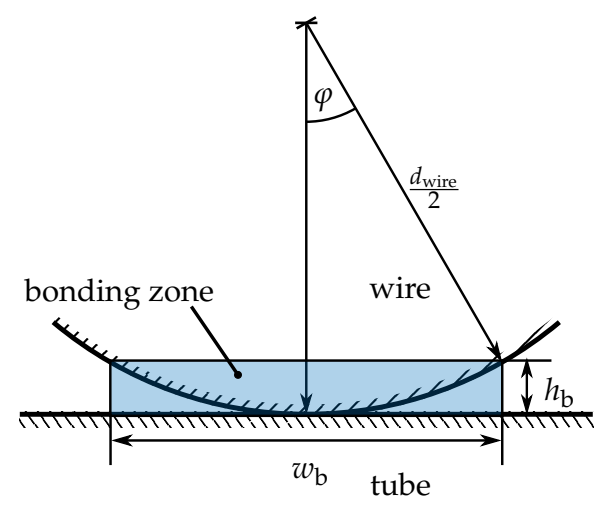

Figure 6. Model of the diffusion bonding zone between tubes and wires.

The resistance value $R$ used in the numerical simulations has been calibrated to match heat transfer rates measured for one operating point, see Figure $7 \mathrm{~b}$. Once $R$ has been determined, the effective mean thermal conductivity of the bonding zone $k_{\mathrm{b}}$ in the fabric can be calculated from Equation (14). See also Yovanovitch et al. [24] in this context. They describe the phenomenon of higher thermal resistance at soldered joints. 


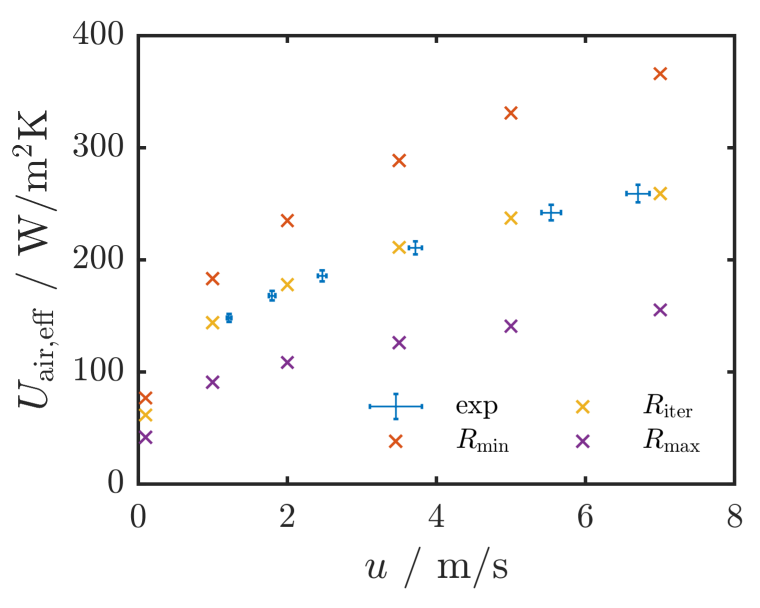

(a)

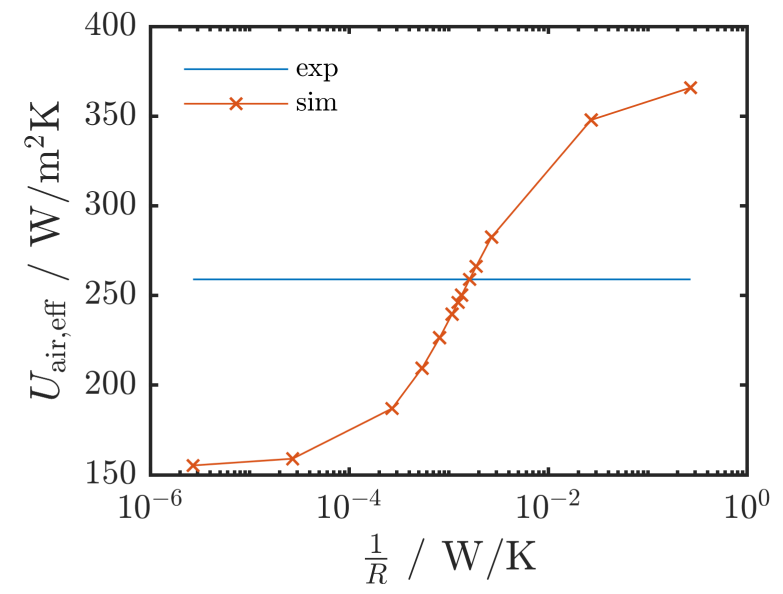

(b)

Figure 7. (a) Effective heat transfer coefficient $U_{\text {air,eff }}$ as a function of inlet velocity $u$. Experimental results and numerical results with variation of thermal resistance $R$. (b) Predicted and measured heat transfer coefficient $U_{\text {air,eff }}$ as a function of reciprocal thermal resistance $1 / R$ at $u=7 \mathrm{~m} / \mathrm{s}$.

Aside from benchmarking thermal performance, as a consequence of (decoupled) fluid flow behavior, accuracy of the simulated velocity and pressure fields has been assessed by comparing air-side mean pressure drop $\Delta p_{\text {air }}$ with experimental data for a range of inflow condition at fixed outflow temperature and outflow static pressure.

\section{Results}

The thermal-hydraulic performance of the wire cloth heat exchanger is addressed in this section. Effective heat transfer coefficient and pressure drop are used to show the performance. The uncertainty of performance data is expressed first as a combined standard uncertainty based on measurement data uncertainty in Appendix B and propagation of uncertainty. Second, an expanded uncertainty is obtained by multiplying the combined standard uncertainty by a coverage factor of 2 . Assuming that the measurement data are normally distributed, $95 \%$ of the data lies in this interval of expanded uncertainty. The expanded uncertainty for $U_{\text {air,eff }}$ is maximum $8 \mathrm{~W} /\left(\mathrm{m}^{2} \mathrm{~K}\right)$; for $\Delta p_{\text {air }}$ it is maximum 1.2 Pa. The energy balance for these measurements is checked by comparing Equation (6) with Equation (7). The values of $\dot{Q}_{\mathrm{HX}}$ have a relative difference of $1 \%$ to maximum $8 \%$.

Thermal performance as a function of contact resistance $R$ between wires and tubes has been analyzed. In the simulations the contact resistance $R$ has been varied between 10 and $10^{5} \mathrm{~K} / \mathrm{W}$. The best agreement between measured and simulated effective heat transfer coefficient $U_{\text {air,eff }}$ was obtained for a contact resistance of $R=625 \mathrm{~K} / \mathrm{W}$. Figure 7 a shows $U_{\text {air,eff }}$ as a function of inlet air velocity $u$ for different contact resistances $R$. $U_{\text {air,eff }}$ increases monotonously with increasing velocity. Figure $7 \mathrm{~b}$ depicts $U_{\text {air,eff }}$ as a function of reciprocal contact resistances for a fixed air velocity $u$. Minimum and maximum values for $U_{\text {air,eff }}$ are up to $40 \%$ lower and $35 \%$ higher than the measured values, within the considered range or $R$.

The contact resistance $R$ was selected so that experimental and numerical values of $U_{\text {air,eff }}$ match for the analyzed case, i.e., $R=625 \mathrm{~K} / \mathrm{W}$ (equivalent to $R^{-1}=1.6 \times 10^{-3} \mathrm{~W} / \mathrm{K}$ ). This yields $k_{\mathrm{b}}=$ $0.26 \mathrm{~W} /(\mathrm{m} \mathrm{K})$ based on Equation (14) and Equations (A1) and (A3) of the appendix. This value for the thermal conductivity is higher than the maximum value expected for a soldered joint [24], but it is still one to two orders of magnitude lower in comparison to a homogeneous solid body of the same material. 
Figure 8 shows the air-side pressure drop for different air-side inflow velocities $u$. The pressure drop increases continuously from $30 \mathrm{~Pa}$ at $u=1 \mathrm{~m} / \mathrm{s}$ to $400-450 \mathrm{~Pa}$ at $u=7 \mathrm{~m} / \mathrm{s}$ and predicted values are found to be up to $15 \%$ higher than experimental measurements.

A selection of averaged quantities measured within the experiment and used for Figures $7 \mathrm{a}$ and 8 are given in the Appendix B.

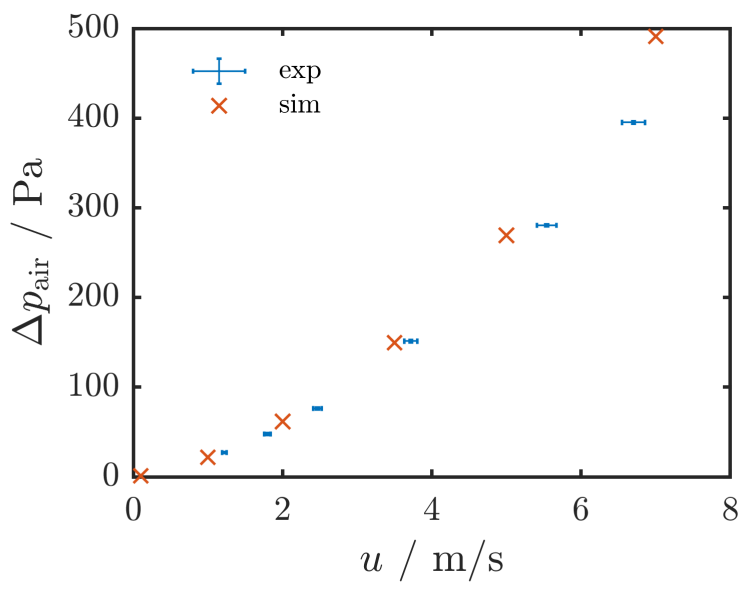

Figure 8. Experimental and numerical results for air-side pressure drop $\Delta p_{\text {air }}$ as a function of the air inlet velocity $u$.

\section{Discussion}

It can be shown that wire cloth micro heat exchangers can be manufactured with a well-developed weaving process and that thermal contact between wires and tubes is acceptable, albeit not ideal. Thus the disadvantages of a wire mesh with wires not contributing to the heat transfer process (e.g., [1-5]) or wires with low heat transfer coefficients due to large wire diameter (e.g., [12,13]) can be overcome.

Predicted pressure drop values are in good agreement with the measurements. For an upstream air velocity of $6 \mathrm{~m} / \mathrm{s}$ the relative difference between calculated and measured values is $16 \%$. This accuracy might be sufficient for preliminary design of sizing considerations. The size of the pressure drop is in a reasonable range for an opaque wire cloth; however, for a heat exchanger of this specific size the values are too high. The pressure drop at $2 \mathrm{~m} / \mathrm{s}$ per length of heat exchanger in air flow direction for very compact louvered fin heat exchangers $\left(\beta>2000 \mathrm{~m}^{2} / \mathrm{m}^{3}\right)$ can be in the range of 2000 to $3500 \mathrm{~Pa} / \mathrm{m} \mathrm{[6]}$. For measured wire cloth the value was $23,000 \mathrm{~Pa} / \mathrm{m}$. However, the produced sample heat exchanger was not designed to provide good thermal-hydraulic performance, but to allow evaluation of the wire cloth manufacturing process and validation of the analysis model. Less dense wire cloths promise a much better hydraulic performance.

Good agreement between predicted and measured thermal performance can be achieved by properly calculating the value of thermal contact resistance $R$ between wires and tubes due to the employed diffusion-bonding process. The value of the contact resistance $R$ is in a reasonable range according to [24]. However, we were not able to verify its value by means of another measurement method. It remains to be shown whether the assumptions employed in the simulation model (such as laminar flow through the wire structure, uniform inflow velocity, uniform wire and tube distances) are adequate or their influence on the result is balanced by the fitted value for the thermal resistance $R$. Additional heat exchanger samples with different geometric parameters and a different material (aluminium) will be available for analysis in the near future. Thus, a matching of thermal resistance values can be done. The main challenge for the manufacturing process will be to produce wire cloths with consistent properties and with very good thermal contact between tubes and wires.

The heat transfer on the air side can be separated in terms of heat transfer on the primary surface (tubes) and on the secondary surface (wires). For the flow around the $2 \mathrm{~mm}$ tubes, Reynolds numbers 
(based on the tube diameter) from 100 to 1000 occur, with eddies shedding from each side of the tube, forming rows of vortices in its wake. This phenomenon allows a mixing of air passing the wires in a main flow area and air in the wake of the tube. Thus, heat transfer on the primary surface can contribute significantly to the overall heat transfer. Apart from that, the secondary surface contributes significantly to the heat transfer. Reynolds numbers (based on wire diameter) range from 10 to 100 . Thus, a steady closed wake flow regime and a laminar vortex shedding regime occur for low and high velocities, respectively. The wire diameter is by a factor of 10 smaller than the tube diameter. This has the effect of a smaller thermal boundary layer on the wire surface and thus a higher local heat transfer coefficient on the wires.

Values for the effective heat transfer coefficient $U_{\text {air,eff }}$ and volumetric surface area density $\beta$ of the measured wire cloth heat exchanger are at the upper range of compact heat exchangers. In comparison to louvered fins the product of $U_{\text {air,eff }}$ and $\beta$ is more than $15 \%$ to $30 \%$ higher for the wire cloth analyzed here [6]. It is assumed that this value will decrease when considering more open structures for the purpose of reducing pressure drop. However, overall dimensions could be preserved by means of different wire arrangements (e.g., twill weave), meandering arrangement of the wire cloth and/or further reduction of tube and wire sizes.

\section{Conclusions}

The main conclusions of this experimental and numerical work on wire cloth micro heat exchangers are as follows:

1. Simulation results showed reasonable agreement with measured data for pressure drop across the wire cloth with relative differences below $16 \%$.

2. The thermal contact between tubes and wires could not be determined independently, thus the thermal contact resistance was fitted with measured data. The fitted value is in good agreement with the values reported in literature.

3. Simulated and measured values for the efficient heat transfer coefficient data are in very good agreement based on the fitted thermal contact resistance.

4. Values for the efficient heat transfer coefficient are strongly dependent on the thermal contact resistance between tubes and wires. A very good contact could yield up to $40 \%$ higher values for the efficient heat transfer coefficient compared to the investigated sample (cf. Figure $7 \mathrm{~b}$ ).

5. The produced and tested sample heat exchanger was not intended to yield a good thermal-hydraulic performance, but did allow evaluation of the employed manufacturing wire cloth process and benchmarking of the simulation model. Therefore, the realised performance is only to a limited extent comparable with other types of heat exchangers. Specifically:

- The achieved effective heat transfer coefficient of $180 \mathrm{WK} / \mathrm{m}^{2}$ at $u=2 \mathrm{~m} / \mathrm{s}$ is in the range of very compact louvered fin heat exchangers, but not superior.

- The pressure drop of the wire cloth heat exchanger sample is very high (by a factor of 7 to 11) compared to louvered fin heat exchangers and with respect to the provided heat transfer surface area.

6. Wire cloth micro heat exchangers provide flexibility in heat exchanger construction. They allow, for example, curved shapes as well as different spacings of the tubes within one heat exchanger.

Correlations for pressure drop and heat transfer characteristics have been developed for a variety of geometrical parameters based on the present simulation model in [19]. These correlations facilitate the design of wire cloth micro heat exchangers for specific applications. Future work on the heat exchanger should focus on the thermal contact between wires and tubes and on more open wire cloth to decrease the pressure drop significantly. Moreover, the possibility to bend the planar wire cloth easily allows considering different shapes of heat exchangers that could be interesting from a design and construction point of view. 
Author Contributions: Conceptualization, H.F. and S.M.; Formal analysis, H.F. and S.M.; Funding acquisition, R.B. and L.S.; Investigation, H.F.; Methodology, H.F. and S.M.; Resources, R.B. and M.B.; Software, S.M.; Supervision, L.S. and C.M.; Validation, H.F. and S.M.; Visualization, H.F. and S.M.; Writing-original draft, H.F. and S.M.; Writing-review and editing, L.S. and C.M. All authors have read and agreed to the published version of the manuscript.

Funding: The authors acknowledge the financial support from the German Federal Ministry for Economic Affairs and Energy (BMWi) for the Thermogewebe Project (FKZ 03ET1281 A-D).

Acknowledgments: We acknowledge the support from Manfred Piesche from IMVT for the supervision of the numerical simulation method. We further want to thank the students Nasir Asadov and Mareike Altenberend for their work on improving the test facility and performing measurements.

Conflicts of Interest: The authors declare no conflict of interest.

\section{Abbreviations}

The following abbreviations are used in this manuscript:

Greek Symbols
$\beta$
$\Delta$
$\gamma$
$\varphi$
$\eta$
$\rho$
$\tau$
$\hat{\sigma}(u)$

heat transfer surface area density $\left(\mathrm{m}^{2} / \mathrm{m}^{3}\right)$

difference of a quantity

angle of contact area tube to wire in y-direction $\left(^{\circ}\right)$

angle of contact area tube to wire in $\mathrm{z}$-direction $\left(^{\circ}\right)$

efficiency (-)

density $\left(\mathrm{kg} / \mathrm{m}^{3}\right)$

stress tensor $\left(\mathrm{kg} /\left(\mathrm{m} \mathrm{s}^{2}\right)\right)$

temporal standard deviation of the velocity $(\mathrm{m} / \mathrm{s})$

Latin Symbols

A

$A_{\mathrm{HTS}}$

$c_{p}$

$d_{\text {tube,outer }}$

$d_{\text {wall }}$

$d_{\text {wire }}$

F

$H_{\text {HXelm }}$

$h$

$h_{\text {air }}$

$h_{\mathrm{b}}$

$h_{\text {water }}$

I

K

$k$

$L_{\text {st }}$

l

$\dot{m}$

$n_{\text {tubes }}$

$\vec{n}$

$p$

$\dot{Q}_{\mathrm{HX}}$

R

$T$

$\Delta T$

$t$

$t_{1}$

$t_{2}$

$U_{\text {air,eff }}$

$U_{\mathrm{HX}}$

$u$

$\vec{u}$

$\dot{V}$

W

$W_{\text {HXelm }}$

$w$

$X$ surface area $\left(\mathrm{m}^{2}\right)$

heat transfer surface area of primary and secondary surface on the air-side $\left(\mathrm{m}^{2}\right)$

heat capacity $(\mathrm{J} /(\mathrm{kg} \mathrm{K}))$

outer tube diameter $\left(\mathrm{m}^{2}\right)$

tube wall thickness $(\mathrm{m})$

wire diameter $(\mathrm{m})$

correction factor for flow configuration (-)

height of heat exchanger $(\mathrm{m})$

enthalpy $(\mathrm{J} / \mathrm{kg})$

air-side heat transfer coefficient $\left(\mathrm{W} /\left(\mathrm{m}^{2} \mathrm{~K}\right)\right)$

height of diffusion bonding zone $(\mathrm{m})$

water-side heat transfer coefficient $\left(\mathrm{W} /\left(\mathrm{m}^{2} \mathrm{~K}\right)\right)$

interface between inner tube wall and water

interface between wire and tube domains

thermal conductivity $(\mathrm{W} /(\mathrm{m} \mathrm{K}))$

length of structure $(\mathrm{m})$

length $(\mathrm{m})$

mass flow rate $(\mathrm{kg} / \mathrm{s})$

number of tubes (-)

normal vector on boundaries $(\mathrm{m})$

pressure $(\mathrm{Pa})$

heat transfer rate within the heat exchanger $(\mathrm{W})$

thermal resistance $(\mathrm{K} / \mathrm{W})$

temperature $(\mathrm{K})$

temperature difference $(\mathrm{K})$

time (s)

wire pitch perpendicular to flow direction $(\mathrm{m})$

tube pitch perpendicular to flow direction $(\mathrm{m})$

effective heat transfer coefficient $\left(\mathrm{W} /\left(\mathrm{m}^{2} \mathrm{~K}\right)\right)$

overall heat transfer coefficient $\left(\mathrm{W} /\left(\mathrm{m}^{2} \mathrm{~K}\right)\right)$

velocity magnitude $(\mathrm{m} / \mathrm{s})$

vector for the velocity field $\left(\mathrm{W} /\left(\mathrm{m}^{2} \mathrm{~K}\right)\right)$

Volume flow rate $\left(\mathrm{m}^{3} / \mathrm{h}\right)$

interface between solid and fluid/air domains

width of heat exchanger (m)

thickness (m)

boundary wall 


$\begin{array}{ll}Y & \text { boundary wall } \\ Z & \text { boundary wall } \\ \begin{array}{l}\text { Subscripts } \\ \text { air }\end{array} & \text { related to the air-side } \\ \text { b } & \text { bonding zone } \\ \mathrm{f} & \text { fin } \\ \mathrm{HX} & \text { heat exchanger } \\ \text { in } & \text { inlet of the heat exchanger } \\ \text { int } & \text { interface } \\ \text { log } & \text { logarithmic mean } \\ \mathrm{m} & \text { mean } \\ \text { out } & \text { outlet of the heat exchanger } \\ \text { s } & \text { related to a straight wire } \\ \text { solid } & \text { solid domain including wires and tube wall } \\ \text { wall } & \text { related to the tube wall } \\ \text { water } & \text { related to the water-side } \\ \text { wire } & \text { related to the wire }\end{array}$

Appendix A. Geometry Parameters of investigated Wire Cloth

$$
\begin{aligned}
l_{\mathrm{b}} & =(200 \mu \mathrm{m}+2 \mathrm{~mm}) \arcsin \left(\frac{200 \mu \mathrm{m}+2 \mathrm{~mm}}{3.5 \mathrm{~mm}}\right)=1.495 \mathrm{~mm} \\
\varphi(10 \mu \mathrm{m}) & =\arccos (1-20 \mu \mathrm{m} / 200 \mu \mathrm{m})=0.451 \mathrm{rad} \\
w_{\mathrm{b}}(0.451 \mathrm{rad}) & =200 \mu \mathrm{m} \sin (0.451 \mathrm{rad})=87.2 \mu \mathrm{m} \\
A_{\mathrm{b}} & =1.495 \mathrm{~mm} \times 87.2 \mu \mathrm{m}=1.3 \times 10^{-7} \mathrm{~m}^{2}
\end{aligned}
$$

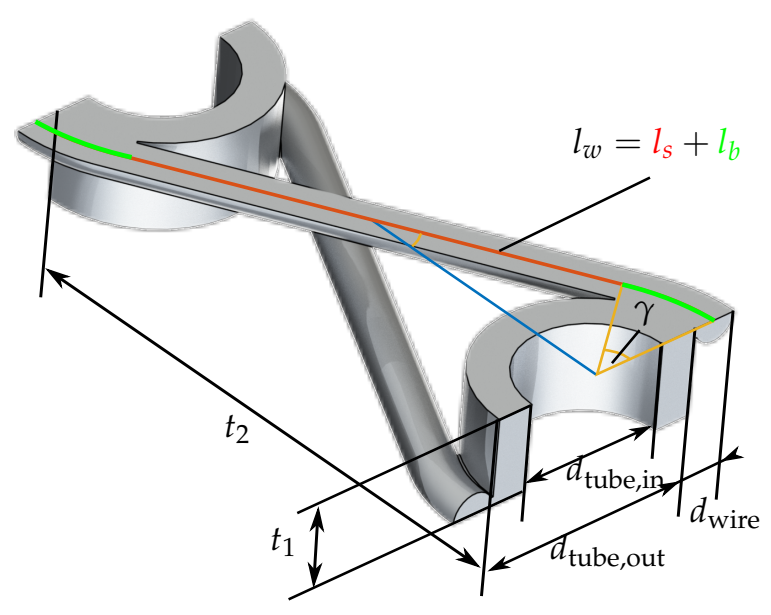

Figure A1. Geometry of the woven wire heat exchanger, diameters and lengths.

\section{Appendix B. Experimental Information}

The installed sensor technology is summarized in Table A1.

A selection of measurement points of the sample shown in Figure 2 is given in Table A2. The level of confidence is expressed in terms of an expanded uncertainty interval.

The water-side heat transfer coefficient ranges for the data in Table A2 from $19 \pm 1.2 \mathrm{~kW} /\left(\mathrm{m}^{2} \mathrm{~K}\right)$ to $25 \pm 1.5 \mathrm{~kW} /\left(\mathrm{m}^{2} \mathrm{~K}\right)$. These values are calculated based on a modified correlation for Nusselt number, Reynolds number and Prandtl number from [20] for developing flows in tubes. The modification decreases the Nusselt number by $13 \%$ to $16 \%$ in order to match with experimental data of $2 \mathrm{~mm}$ tubes tested at Fraunhofer ISE previously. 
Table A1. Major sensor technology installed at test rig for heat exchangers [7]. Standard uncertainty has rectangular distribution.

\begin{tabular}{lllll}
\hline Domain & Measured Variable & Technolgy & Range & Standard Uncertainty \\
\hline air & temperature & thin Pt100 & $5-90^{\circ} \mathrm{C}$ & $0.05 \mathrm{~K}$ \\
air & volume flow rate & ultrasonic flow meter & $10-270 \mathrm{~m}^{3} / \mathrm{h}$ & $2 \%$ of meas. value \\
air & volume flow rate & orifice plate & $150-1000 \mathrm{~m}^{3} / \mathrm{h}$ & $2 \%$ of meas. value \\
air & pressure drop & differential pressure transmitter & $0-50 \mathrm{~Pa}$ & $0.1 \mathrm{~Pa}$ \\
air & pressure drop & differential pressure transmitter & $0-250 \mathrm{~Pa}$ & $1 \mathrm{~Pa}$ \\
air & absolute pressure & barometric pressure sensor & $500-1100 \mathrm{hPa}$ & $0.3 \mathrm{hPa}$ \\
water & temperature & Pt100 rod sensor & $5-90^{\circ} \mathrm{C}$ & $0.05 \mathrm{~K}$ \\
water & volume flow rate & electromagnetic flow sensor & $0-7.2 \mathrm{~m}^{3} / \mathrm{h}$ & $0.4 \%$ of meas. value \\
water & pressure drop & differential pressure transmitter & $0-0.6 \mathrm{bar}$ & $3 \mathrm{mbar}$ \\
\hline
\end{tabular}

Table A2. Selection of measurement points with expanded uncertainty interval shown by $\pm x$.

\begin{tabular}{ccccccc}
\hline$\dot{V}_{\text {air }}\left(\mathrm{m}^{3} / \mathrm{h}\right)$ & $\dot{\boldsymbol{V}}_{\text {water }}\left(\mathrm{m}^{3} / \mathrm{h}\right)$ & $T_{\text {air,in }}\left({ }^{\circ} \mathrm{C}\right)$ & $T_{\text {air,out }}\left({ }^{\circ} \mathrm{C}\right)$ & $T_{\text {water,in }}\left({ }^{\circ} \mathrm{C}\right)$ & $T_{\text {water,out }}\left({ }^{\circ} \mathrm{C}\right)$ & $\Delta p_{\text {air }}(\mathrm{Pa})$ \\
\hline $169 \pm 4$ & $0.89 \pm 0.004$ & $24.5 \pm 0.12$ & $50.4 \pm 0.12$ & $84 \pm 0.12$ & $165.4 \pm 0.12$ & $54 \pm 0.6$ \\
$169 \pm 4$ & $1.08 \pm 0.004$ & $24.4 \pm 0.12$ & $50.5 \pm 0.12$ & $84.1 \pm 0.12$ & $166 \pm 0.12$ & $54 \pm 0.6$ \\
$250 \pm 6$ & $1.08 \pm 0.004$ & $24.3 \pm 0.12$ & $45.6 \pm 0.12$ & $84.1 \pm 0.12$ & $165.6 \pm 0.12$ & $96 \pm 1.2$ \\
$251 \pm 6$ & $0.89 \pm 0.004$ & $24.4 \pm 0.12$ & $45.4 \pm 0.12$ & $84 \pm 0.12$ & $165 \pm 0.12$ & $96 \pm 1.2$ \\
$346 \pm 8$ & $1.08 \pm 0.004$ & $24.3 \pm 0.12$ & $42 \pm 0.12$ & $84.1 \pm 0.12$ & $165.2 \pm 0.12$ & $152 \pm 1.2$ \\
$346 \pm 8$ & $0.89 \pm 0.004$ & $24.4 \pm 0.12$ & $41.9 \pm 0.12$ & $84 \pm 0.12$ & $164.4 \pm 0.12$ & $152 \pm 1.2$ \\
$526 \pm 12$ & $1.08 \pm 0.004$ & $24.4 \pm 0.12$ & $38.1 \pm 0.12$ & $84.1 \pm 0.12$ & $164.6 \pm 0.12$ & $304 \pm 1.2$ \\
$526 \pm 12$ & $0.89 \pm 0.004$ & $24.5 \pm 0.12$ & $38.1 \pm 0.12$ & $84 \pm 0.12$ & $163.6 \pm 0.12$ & $302 \pm 1.2$ \\
$790 \pm 18$ & $0.89 \pm 0.004$ & $24.6 \pm 0.12$ & $35 \pm 0.12$ & $83.2 \pm 0.12$ & $161.2 \pm 0.12$ & $558 \pm 1.2$ \\
$790 \pm 18$ & $1.08 \pm 0.006$ & $24.5 \pm 0.12$ & $35.3 \pm 0.12$ & $84.1 \pm 0.12$ & $163.8 \pm 0.12$ & $564 \pm 1.2$ \\
$959 \pm 22$ & $0.89 \pm 0.004$ & $24.7 \pm 0.12$ & $33.6 \pm 0.12$ & $81.5 \pm 0.12$ & $157.6 \pm 0.12$ & $790 \pm 1.2$ \\
$961 \pm 22$ & $1.08 \pm 0.006$ & $24.6 \pm 0.12$ & $34.1 \pm 0.12$ & $84.1 \pm 0.12$ & $163.4 \pm 0.12$ & $790 \pm 1.2$ \\
\hline
\end{tabular}

\section{References}

1. $\mathrm{Xu}$, J.; Tian, J.; Lu, T.J.; Hodson, H.P. On the thermal performance of wire-screen meshes as heat exchanger material. Int. J. Heat Mass Transf. 2007, 50, 1141-1154, doi:10.1016/j.ijheatmasstransfer.2006.05.044. [CrossRef]

2. Prasad, S.B.; Saini, J.S.; Singh, K.M. Investigation of heat transfer and friction characteristics of packed bed solar air heater using wire mesh as packing material. Sol. Energy 2009, 83, 773-783, doi:10.1016/j.solener.2008.11.011. [CrossRef]

3. Fugmann, H.; Laurenz, E.; Schnabel, L. Wire Structure Heat Exchangers-New Designs for Efficient Heat Transfer. Energies 2017, 10, 1341, doi:10.3390/en10091341. [CrossRef]

4. Liu, Y.; Xu, G.; Luo, X.; Li, H.; Ma, J. An experimental investigation on fluid flow and heat transfer characteristics of sintered woven wire mesh structures. Appl. Therm. Eng. 2015, 80, 118-126, doi:10.1016/j.applthermaleng.2015.01.050. [CrossRef]

5. Fugmann, H.; Tahir, A.J.; Schnabel, L. Woven Wire Gas-To-Liquid Heat Exchanger. In World Congress on Mechanical, Chemical and Material Engineering; MCM15., Ed.; Avestia Publishing, International ASET Inc.: Ottawa, ON, Canada, 2015.

6. Fugmann, H.; Di Lauro, P.; Sawant, A.; Schnabel, L. Development of Heat Transfer Surface Area Enhancements: A Test Facility for New Heat Exchanger Designs. Energies 2018, 11, 1322, doi:10.3390/en11051322. [CrossRef]

7. Fugmann, H. Investigation of Wire Structures for Heat Transfer Enhancement in Compact Heat Exchangers. Ph.D. Thesis, Karlsruher Institut für Technologie, Karlsruhe, Germany, 2019, doi:10.5445/IR/1000099544. [CrossRef]

8. Chen, L.; Wirtz, R.A. Development of a high performance heat sink based on screen-fin technology. In Proceedings of the Ninteenth Annual IEEE Semiconductor Thermal Measurement and Management Symposium, San Jose, CA USA, 11-13 March 2003; pp. 53-60, doi:10.1109/STHERM.2003.119433. [CrossRef]

9. van Andel, E.; van Andel, E. Heat Exchanger and Applications Thereof. Patent US7963067 B2, 21 June 2011. 
10. Bonestroo, J.P. Calculation Model of Fine-Wire Heat Exchanger. Master's Thesis, Twente University, Enschede, The Netherlands, 2012.

11. Fugmann, H.; Schnabel, L.; Frohnapfel, B. Heat transfer and pressure drop correlations for laminar flow in an in-line and staggered array of circular cylinders. Numer. Heat Transf. Part A Appl. 2019, 75, 1-20, doi:10.1080/10407782.2018.1562741. [CrossRef]

12. Kumra, A.; Rawal, N.; Samui, P. Prediction of Heat Transfer Rate of a Wire-on-Tube Type Heat Exchanger: An Artificial Intelligence Approach. Procedia Eng. 2013, 64, 74-83, doi:10.1016/j.proeng.2013.09.078. [CrossRef]

13. Lee, T.H.; Yun, J.Y.; Lee, J.S.; Park, J.J.; Lee, K.S. Determination of airside heat transfer coefficient on wire-on-tube type heat exchanger. Int. J. Heat Mass Transf. 2001, 44, 1767-1776, doi:10.1016/S0017-9310(00)00201-5. [CrossRef]

14. van Andel, E. Heat Exchanger and Method for Manufacturing Same. Patent EP0714500 B1, 7 January 1999.

15. Balzer, R. Wärmetauschvorrichtung für einen Wärmeaustausch zwischen Medien und Webstruktur. Patent DE102006022629, 15 November 2007.

16. Balzer, R.; Fugmann, H.; Schnabel, L. Wire Cloth Micro Heat Exchanger with High Pressure Stability. In Compact Heat Exchangers: Designs, Materials and Applications; Krüssmann, H., Ed.; PP Publico Publications: Essen, Germany, 2018.

17. Radermacher, R.; Bacellar, D.; Aute, V.; Huang, Z.; Hwang, Y.; Ling, J.; Muehlbauer, J.; Tancabel, J.; Abdelaziz, O.; Zhang, M. Miniaturized Air-to-Refrigerant Heat Exchangers; University of Maryland: College Park, MD, USA, 2017, doi:10.2172/1358252. [CrossRef]

18. VDI. VDI-Wärmeatlas; Springer: Berlin, Germany, 2013.

19. Martens, S. Modellierung und numerische Berechnung der thermofluiddynamischen Eigenschaften gewebebasierter Wärmeübertrager. Ph.D. Thesis, Universität Stuttgart, Stuttgart, Germany, 2019.

20. Shah, R. K.; Sekulić, D.P. Fundamentals of Heat Exchanger Design; Wiley: Hoboken, NJ, USA, 2003.

21. Nicholas, M.G.; Crispin, R.M. Diffusion bonding stainless steel to alumina using aluminium interlayers. J. Mater. Sci. 1982, 17, 3347-3360, doi:10.1007/BF01203505. [CrossRef]

22. Mahendran, G.; Balasubramanian, V.; Senthilvelan, T. Influences of diffusion bonding process parameters on bond characteristics of Mg-Cu dissimilar joints. Trans. Nonferrous Met. Soc. China 2010, 20, 997-1005, doi:10.1016/S1003-6326(09)60248-X. [CrossRef]

23. Nakaso, K.; Mitani, H.; Fukai, J. Convection heat transfer in a shell-and-tube heat exchanger using sheet fins for effective utilization of energy. Int. J. Heat Mass Transf. 2015, 82, 581-587, doi:10.1016/j.ijheatmasstransfer.2014.11.033. [CrossRef]

24. Yovanovich, M.M.; Tuarze, M. Experimental Evidence of Thermal Resistance at Soldered Joints. J. Spacecr. Rockets 1969, 6, 855-857, doi:10.2514/3.59620. [CrossRef]

(C) 2020 by the authors. Licensee MDPI, Basel, Switzerland. This article is an open access article distributed under the terms and conditions of the Creative Commons Attribution (CC BY) license (http://creativecommons.org/licenses/by/4.0/). 